\title{
Renda de Bilros: estudo de pontos tecidos nas regiões Nordeste e Sul do Brasil
}

Bobbin Lace: study of the stitches woven in the northeastern and southern regions of Brazil

\author{
Vera Lucia Felippi da Silva \\ Mestre, Universidade Federal do Rio Grande do Sul, RS \\ verafelippi@hotmail.com \\ Gabriela Trindade Perry \\ Doutora, Universidade Federal do Rio Grande do Sul, RS \\ gabriela.perry@ufrgs.com.br
}




\section{Renda de Bilros: estudo de pontos tecidos nas regiões Nordeste e Sul do Brasil}

Bobbin Lace: study of the stitches woven in the northeastern and southern regions of Brazil

Vera Lucia Felippi da Silva, Gabriela Trindade Perry

\section{Resumo}

Considerando a importância histórica, cultural e social da produção de renda de bilros no Brasil, este estudo abrange aspectos imateriais e materiais deste patrimônio, tendo como objetivo fazer uma reflexão sobre como são tratados pontos de renda de bilros, considerando suas nomenclaturas e estruturas têxteis, tendo como recorte geográfico dois extremos do país: a região sul e a região nordeste. Essas regiões se destacam pela produção artesanal da renda e pesquisas científica sobre o tema. Para alcançar o objetivo foram estudados 61 pontos e observou-se que apenas $39,5 \%$ destes pontos são conhecidos em ambas as regiões. Trata-se de um estudo qualitativo, de natureza aplicada, fundamentado em pesquisa bibliográfica, documental e visita técnica.

Palavras-chave: renda de bilros, pontos de renda de bilros, patrimônio brasileiro

\section{Abstract}

Considering the historical, cultural and social importance of the production of bobbin lace in Brazil, this study covers immaterial and material aspects of this heritage, aiming to make a reflection on how the bobbin lace stitches are treated, considering their nomenclatures and textile structures, having as geographic cut two extremes of the country: the southern region and the northeast region. These regions stand out for the artisanal lace production and scientific research on the theme. To reach the goal, 61 stitches were studied and it was observed that only 39.5\% of these stitches are known in both regions. It is a qualitative study, based on bibliographical and documental research and technical visit.

Keywords: bobbin lace, bobbin lace stitches, Brazilian heritage 


\section{Introdução}

A produção de rendas é uma das principais técnicas artesanais encontradas no Brasil. No cenário nacional, 7,5\% dos municípios tem vínculo com a produção artesanal de rendas, ou seja, em 415 municípios há registros da presença de rendas, os quais estão assim distribuídos: região nordeste com 223 municípios, região sudeste com 91 municípios, região sul com 69 municípios, região centrooeste com 20 municípios e região norte com 12 municípios (SEBRAE, 2008). Vale ressaltar que neste universo estão inseridas técnicas de rendas como: bilros, labirinto, renascença, irlandesa, filé, frivolité, entre outras. De acordo com o Serviço Brasileiro de Apoio às Micro e Pequenas Empresas-Sebrae (2008), a região nordeste se destaca pela diversidade de técnicas de rendas produzidas, pela quantidade de cidades envolvidas e pelo fluxo de turistas, seguida pela região sudeste e sul.

Esta pesquisa se concentra no estudo das rendas de bilros, especificamente da região nordeste e da região sul. As atividades nestas duas regiões em torno da técnica refletem e contribuem com a produção científica sobre 0 tema. Em ambas as regiões, tais produções científicas estão vinculadas à tecelagem de renda de bilros em pequenas comunidades produtoras com enfoque em áreas do conhecimento como ciências sociais, engenharia de produção e psicologia (Balbinot et al 2012; Almeida, 2010; Cordeiro, 2010; Barros, 2009).

Nestas pesquisas sobre renda de bilros no país percebe-se que há uma lacuna no que diz respeito ao estudo dos pontos e suas nomenclaturas. Matsusaki (2013, p.95) reforça esta lacuna e comenta que "seria necessário que se fizesse um levantamento para apontar os pontos existentes em cada localidade, traçando também um comparativo dos nomes usados pelas rendeiras, para que se pudesse obter um catálogo dos pontos da renda de bilros". Considerando esta questão, o objetivo deste estudo é fazer uma reflexão de como são tratados os pontos de renda de bilros a partir de comparações das nomenclaturas e da estrutura têxtil desses pontos nas duas regiões do país: a região nordeste e a região sul, tendo como recortes geográficos o Estado do Ceará e o Estado de Santa Catarina. 
Para alcançar este objetivo, o estudo baseou-se em duas publicações: "Renda de Bilros" de Valdelice Girão (2013) e "Renda de Bilros: um legado açoriano transcendendo séculos em Florianópolis", de Maria Armênia Wendhousen (2015).

O ponto de partida foram 61 diferentes tipos de pontos que constam no livro de Girão (2013), os quais foram confrontados com os termos apresentados na publicação de Wendhousen (2015). Além da teoria, o estudo incluiu a visita a artesãs da Associação de Rendeiras de Sambaqui, localizada no norte da cidade de Florianópolis/SC, para verificar como é tratada, na prática, tal questão. A Associação, local de encontro e comercialização de rendas, existe há cinco anos e conta com dez artesãs associadas, as quais tem longa experiência na arte de tecer renda de bilros.

Além de identificar nomenclaturas em comum entre as duas regiões, pretende-se também apontar as diferenças, pluralidades, potencialidades e riquezas culturais da tradição do fazer rendas, questões estas que se inserem no âmbito de discussão do patrimônio imaterial. Assim, as questões de patrimônio imaterial são também associadas à materialidade do objeto abrangendo as ferramentas utilizadas na produção de rendas de bilros.

O estudo forneceu subsídios para sinalizar e reforçar a riqueza desta cultura, bem como demonstrar que a maior parte dos pontos elencados pertencentes à região nordeste são desconhecidos na região sul. Além disso, os pontos que são formalmente iguais muitas vezes são tratados por nomes diferentes. Retrata-se aqui uma situação em que, ao mesmo tempo em que se demonstra a riqueza do tema em si, sinaliza para uma possível dificuldade de comunicação devido a diversidade de pontos e seus respectivos nomes. Devido a isso, necessitou-se vincular os nomes às imagens para se certificar do objeto analisado. Além disso, sob outro ponto de vista, reforça que o vocabulário empregado está vinculado ao contexto de cada comunidade, às suas vivências, às suas tradições e à cultura do local. Assim, este estudo contribui para divulgar este conhecimento e minimizar o choque das diferenças na compreensão da nomenclatura dos pontos de renda de bilros para os interessados que desejem se inserir ou interagir com artesãos para desenvolvimento de projetos ligados à renda de bilros nestas duas regiões. 
Concluiu-se que a criação de um catálogo de pontos é viável, porém requer um longo trabalho de pesquisa nas diversas comunidades produtoras de rendas no país. Este trabalho de campo torna-se necessário para a verificação das alterações e adaptações que os nomes tiveram em função das mudanças de localidade.

\section{Renda de bilros: o patrimônio cultural no Brasil}

No Brasil, diz-se renda de bilros, em inglês bobbin lace, em italiano merletto a fuselli e em francês dentele aux fuseaux. Conforme Earnshaw (2000), o registro mais antigo desta técnica, em livros, é de 1536 no livro de padrões de Zurique e, em seguida, dois outros livros foram publicados no século XVI: Le Pompe (1557) e Parasole (1595). O nome da renda está diretamente ligado à principal ferramenta utilizada para tecê-la: os bilros.

Os bilros são hastes, em sua grande maioria feitos de madeira, ou a partir da combinação de madeira com outros materiais, como ossos, vidros ou marfim. Segundo Girão (2013), os bilros feitos no Brasil, se comparado com bilros europeus, são considerados menos elaborados.

Geralmente as formas dos bilros variam nos diferentes países, ou até mesmo nas diferentes regiões de cada país, mas de maneira geral possuem uma "cabeça", um "pescoço" onde os fios são enrolados e o cabo, o qual pode conter diferentes formatos e ornamentações. O "pescoço" varia de comprimento, sendo a espessura do fio que determina sua medida (Earnshaw, 1988).

O Lace Study Centre, um importante centro de estudos de rendas ligados ao PowerHouse Museum da Austrália, descreve a renda de bilros como a forma de tecer, na qual os fios de urdume e de trama são constantemente trocados de lugar. A movimentação dos bilros é orientada pelo tipo de ponto empregado na renda.

Etcheverry (2013) atribui a possibilidade da renda de bilros ter surgido em meados do século XVI a partir da técnica de macramê, já que ambos trabalham com fios com as extremidades livres e em pares. Porém no macramê os fios são estruturados a partir de nós para formar os pontos e, na renda de bilros, os fios são 
cruzados e/ou torcidos. Aponta ainda que o uso dos bilros foi um avanço importante na realização das rendas por ser mais rápido que outra técnica conhecida e muito utilizada na época de seu surgimento, a renda de agulha.

Países europeus como França, Itália, Espanha, Portugal, Inglaterra e Holanda são os que mais se destacaram na produção de renda de bilros (Etcheverry, 2013; Earnshaw, 2000). No Brasil ocorreu a inserção deste tipo de técnica a partir da chegada de $\mathrm{D}$. João VI com a corte portuguesa e o contato com a Inglaterra e a França, que colaboraram para uma aproximação de costumes europeus (Costa, 2000). Foram os eventos sociais promovidos pela corte que fez surgir a necessidade de uso de roupas elaboradas e adornadas. Porém, de acordo com Ramos (1948), quase não há relatos sobre a origem das rendas no Brasil:

\begin{abstract}
Infelizmente os dados históricos são praticamente inexistentes, pois a renda de bilros, entre nós, como, aliás toda e qualquer forma de artesanato, jamais mereceram a menor proteção ou orientação oficiais, e são deixados aos azares da improvisação, o que significa abandono quase completo. As referências de alguns documentos oficiais a "rendas", nos primeiros tempos, dizem respeito às rendas de procedência europeia, francesas, italianas ou flamengas, utilizadas nas vestes das classes abastadas [...] As nossas humildes rendeiras, em cujas mãos até hoje vem se mantendo 0 artesanato das rendas, continuam no anonimato do seu árduo labor, apesar de alguns esforços mais recentes em reconhecer-lhes o mérito. Alguma alusão incidental, aqui e ali, indica apenas de leve a procedência portuguesa da sua arte popular. (Ramos, 1948, p. 35-36)
\end{abstract}

Talvez o registro mais antigo sobre a renda feita no Brasil tenha sido em 1869 no livro de Palliser onde há um breve relato comentando que neste país se faz uma renda de bilros estreita e grosseira para o consumo doméstico. Uma das contribuições para esta falta de registro provavelmente esteja vinculado ao ensino da técnica, visto que não há registro de aprendizado formal para tecer a renda de bilros. Diferente da situação na cidade de Buenos Aires do final do século XIX, onde há registros decorrentes do curso de rendas de bilros criado por escolas ligadas ao Ministério da Educação. Estes cursos eram voltados a todos os setores sociais e tinha a duração de três anos (Etcheverry, 2013).

Mesmo não havendo um aprendizado formal no Brasil, Brussi (2009) questiona-se como se explicaria a rápida difusão da técnica, tanto geográfica quanto social. A autora sugere que tal difusão tenha se dado por vias não oficiais, onde o saber-fazer da renda de bilro 
Percorreu vias consideradas 'informais', como aquelas do parentesco, da amizade e da vizinhança. Nesse sentido, a casa se apresenta como espaço privilegiado de incorporação de tais hábitos e habilidades. (Brussi, 2009, p.24)

Realidade que se verifica ainda hoje no quotidiano de diversas comunidades produtoras de rendas.

Tais comunidades estão inseridas nas principais regiões receptoras deste conhecimento, sendo elas o sul e o nordeste. Na região sul, devido à imigração açoriana e, no nordeste, pela influência holandesa desde o século XVII (Brussi, 2009). Independente da discussão de qual lugar foi o primeiro a absorver a técnica, o fato é que dentre todas as rendas aqui produzidas, a renda de bilros foi a que mais se espalhou pelo país. No seu início era tecida por mulheres de todas as camadas sociais, mas atualmente sua produção se concentra em comunidades de artesãs, muitas vezes apoiadas por instituições públicas, privadas e voluntários que se movimentam e lançam projetos no sentido de valorizar a atividade, contribuir com o repasse do conhecimento e de dar visibilidade para o trabalho.

Nas regiões produtoras se concentra toda a riqueza cultural, visual e técnica ou, conforme aponta Ganem (2013, p. 31) "um expressivo legado artesanal no espaço contemporâneo". A autora traz considerações importantes sobre este saber-fazer:

Muito se mantém das velhas formas e heranças relacionadas a essa prática, as rendeiras repetem o velho hábito de trançar fios e histórias, desde muito jovens, mantendo esta atividade por toda uma vida, portanto existe um alto nível de especialização nesta atividade, contudo, historicamente, há uma incompreensão do valor material e imaterial existente nestes fazeres e saberes. (Ganem, 2013. p.86)

Ganem (2013), em uma referência ao aprofundamento das questões de diálogo entre design/artesanato e tradição/inovação aponta que o artesanato tradicional representa uma cultura e esta percepção indica a necessidade (e também urgência) da compreensão de sua riqueza. Riqueza esta que se vincula às duas dimensões de patrimônio cultural: o material e o imaterial.

Neste estudo, pelo fato do foco estar vinculado à comparação da nomenclatura dos pontos não podemos deixar de reforçar que tal tema está ligado a um patrimônio cultural imaterial, sendo este o que está ligado aos saberes, as habilidades, às crenças e às práticas. É um conhecimento que muitas vezes não foi 
ensinado por livros ou registros formais e que se transmite oralmente de geração para geração. O Instituto do Patrimônio Histórico e Artístico Nacional-IPHAN, em seu site, aponta que os bens culturais de natureza imaterial dizem respeito às práticas $\mathrm{e}$ aos domínios da vida social que se manifestam em saberes, ofícios e modos de fazer; celebrações; formas de expressão cênicas, plásticas, musicais ou lúdicas; técnicas tradicionais artesanais e nos lugares como mercados, feiras e santuários que abrigam práticas culturais coletivas. Dentre as tipologias de rendas feitas no Brasil, o modo de fazer renda irlandesa de Divina Pastora-SE está elencado como bem imaterial e o bico e a renda singeleza estão em processo de registro.

Para a Organização das Nações Unidas para a Educação, Ciência e Cultura-UNESCO, o patrimônio imaterial é particularmente vulnerável uma vez que está em constante mutação e multiplicação de seus portadores. Por isso, em 2003 passou a ser adotada a Convenção para a Salvaguarda do Patrimônio Cultural Imaterial, um documento que uniu estudos técnicos e discussões internacionais com especialistas, juristas e membros de governos. Por salvaguarda, a UNESCO considera todas

As medidas que visam assegurar a viabilidade do património cultural imaterial, incluindo a identificação, documentação, investigação, preservação, proteção, promoção, valorização, transmissão essencialmente pela educação formal e não formal - e revitalização dos diversos aspectos deste património. (UNESCO, 2006)

A entidade reforça que:

Além das gravações, registros e arquivos, a UNESCO considera que uma das formas mais eficazes de preservar o patrimônio imaterial é garantir que os portadores desse patrimônio possam continuar produzindo-o e transmitindo-o. Assim, a Organização estimula os países a criarem um sistema permanente de identificação de pessoas (artistas, artesãos etc.) que encarnam, no grau máximo, as habilidades e técnicas necessárias para a manifestação de certos aspectos da vida cultural de um povo e a manutenção de seu patrimônio cultural material. (UNESCO, 2006)

A urgência em reconhecer as riquezas do contexto da renda de bilros mencionada por Ganem e o reconhecimento deste patrimônio associa-se ao fato de que tal conhecimento caminha para um futuro incerto e que pouco se pode prever. Se por um lado ampliam-se trabalhos e pesquisas acadêmicas a respeito do tema, por outro a maioria destas pesquisas apontam que esta técnica corre um sério risco de se extinguir. Isto porque muitos jovens não se interessam no aprendizado, principalmente pelo baixo rendimento financeiro que a atividade traz. Diante desta 
constatação, toda a movimentação voltada para estimular esta prática é importante para garantir sua existência. Ganem (2013, p. 68) aponta que se o objeto perde seu uso e função no espaço contemporâneo possivelmente ele pode se extinguir e "pode, até mesmo, virar uma obra de arte, uma peça de museu, mas isso não é capaz de manter uma cultura produtiva".

As técnicas de rendas, de uma maneira geral, estão evoluindo negativamente, conforme aponta a publicação Cultura em Números, divulgada em 2010 pelo Ministério da Cultura, que demonstra os números de locais de produção de rendas artesanais e claramente se percebe um decréscimo relevante (tabela 1). Mesmo sendo dados dos anos de 2005 e 2006, e divulgados em 2010, o levantamento contribui para alertar o que pode estar acontecendo com um importante patrimônio nacional.

\begin{tabular}{|l|c|c|c|}
\hline \multicolumn{1}{|c|}{ Região } & $\begin{array}{c}\text { Ano 2005 } \\
\text { Número de } \\
\text { municípios }\end{array}$ & $\begin{array}{c}\text { Ano 2006 } \\
\text { Número de } \\
\text { municípios }\end{array}$ & Evolução \% \\
\hline Norte & 16 & 12 & $-25 \%$ \\
\hline Nordeste & 309 & 223 & $-27,8$ \\
\hline Sudeste & 115 & 91 & $-20,9$ \\
\hline Sul & 112 & 69 & $-38,4$ \\
\hline Centro-Oeste & 33 & 20 & $-39,4$ \\
\hline
\end{tabular}

Tabela 1: Evolução da atividade artesanal de rendas no Brasil. (IBGE/MUNIC. Elaboração MinC, 2010)

Verifica-se, portanto, no quadro acima que em nenhuma região do país a produção de rendas teve uma evolução positiva. Mesmo sendo um quadro elaborado no qual se inserem todas as técnicas de renda, sua menção nesta pesquisa serve como uma forma de alertar para o cenário de evolução negativa incentivar atividades de ordem prática para os possíveis agentes (por exemplo, designers) com interesse em interagir neste universo. Sendo assim e visando a compreensão do universo de produção de rendas de bilros, na sequencia tratamos das especificidades da área. 


\section{A produção de renda de bilros: instrumentos, usos e elementos}

\section{constitutivos}

Para tecer renda de bilros são necessários basicamente os seguintes instrumentos: os bilros, a almofada, o molde e alfinetes. Os bilros foram mencionados anteriormente pelo fato de dar o nome a esta técnica de renda. As almofadas, no Brasil, costumam ser feitas de tecidos de algodão com um formato cilíndrico e preenchidos por capim, palha de bananeira ou serragem. Os moldes, também conhecidos como pique, normalmente são feitos de papelão grosso onde se perfura o desenho da renda. Na cidade de Florianópolis foi identificada uma alteração nesta etapa, pois algumas artesãs usam uma fotocópia de renda pronta, feito em papel branco, para orientar a renda a ser tecida. Se antes a representação era feita em papelão contendo "riscos" e furos feitos com alfinetes, agora são fotocópias de rendas já prontas que cumprem o papel de molde, conforme pode ser observado nas Figuras 1 e 2, respectivamente.

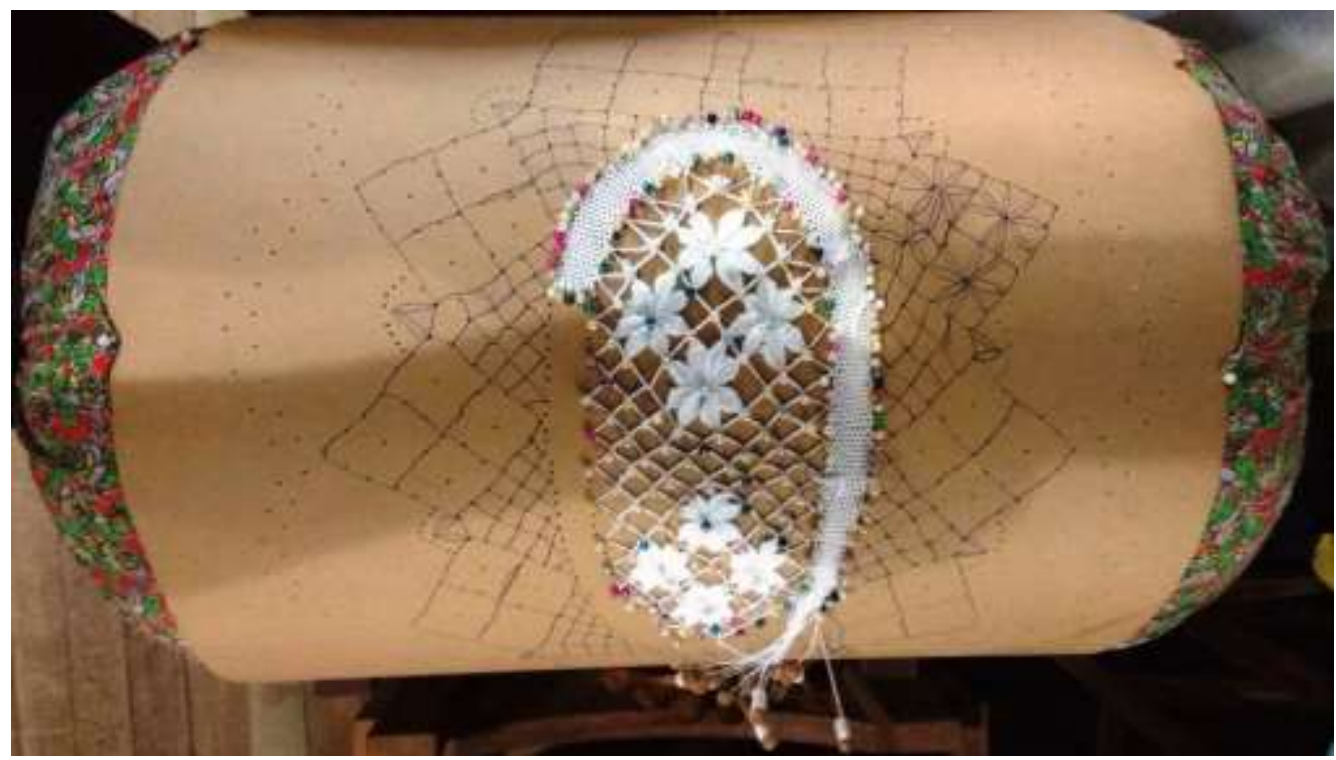

Figura 1: Forma tradicional de pique: papelão com riscos e furos ( $\mathrm{A}$ autora) 


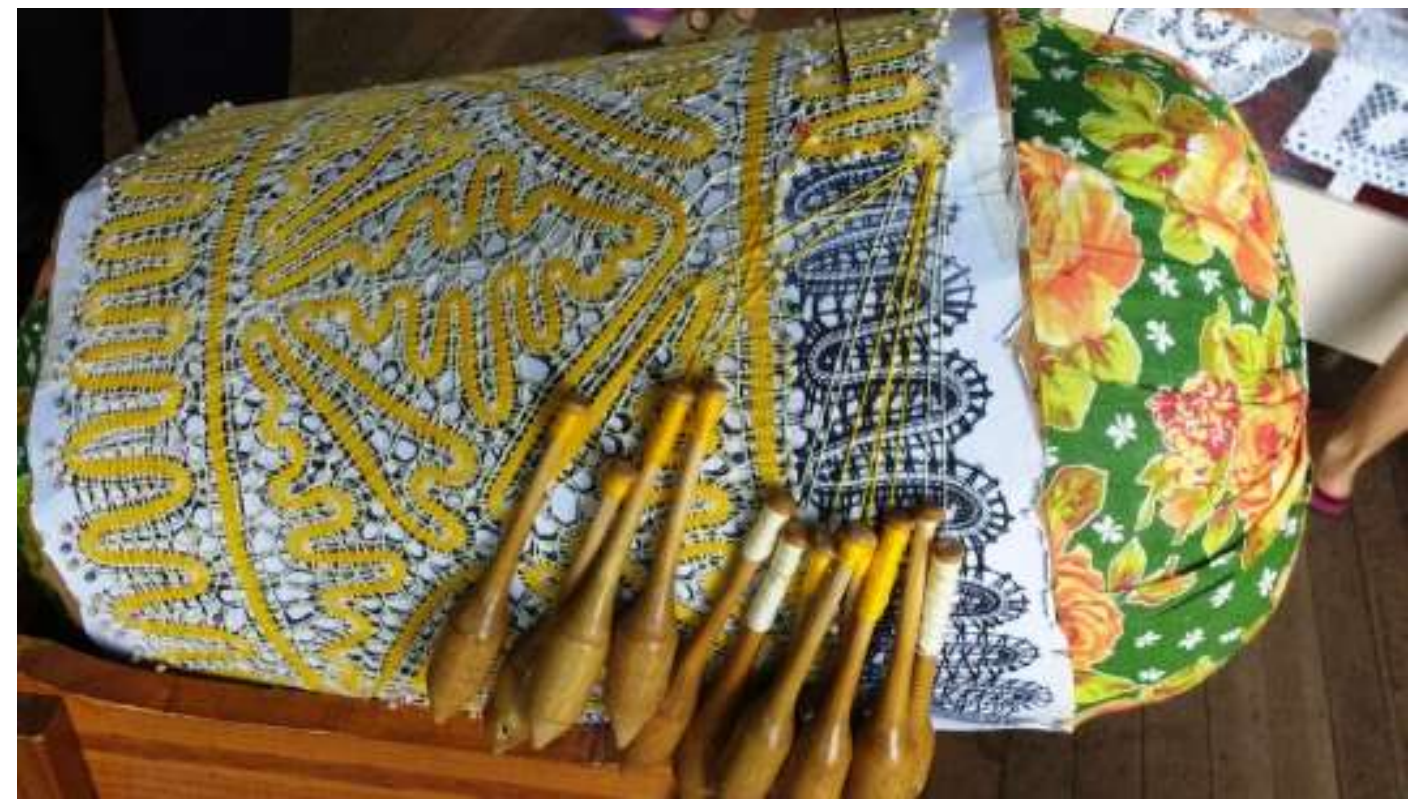

Figura 2: Novo formato de pique identificado em Florianópolis e utilizado por algumas rendeiras: papel branco com fotocópia da renda a ser tecida (A autora)

As Figuras 1 e 2 foram obtidas em visita ao Casarão da Rendeira, no bairro Lagoa da Conceição, na cidade de Florianópolis e podemos ver claramente a diferença nos moldes presos às almofadas. Como é de costume, as rendeiras dificilmente criam novos desenhos de rendas e, fazendo uso das fotocópias, essa situação se reforça. As cópias são trocadas entre elas e reproduzidas sempre que necessário. Além disso, segundo Wendhausen (2015) é prático pela facilidade de ampliação e/ou redução do molde, o qual foi possível verificar na prática conforme Figura 2. E, por último, os alfinetes os quais são presença constante durante a tecelagem da renda, os quais substituíram os espinhos usados em épocas remotas, tendo como finalidade apoiar e direcionar os bilros no trabalho de tecer a renda.

De acordo com Earnshaw (1983) as rendas de bilros podem ser divididas em dois principais grupos: as contínuas e as não-contínuas. Na renda contínua a base de ligação entre os motivos e, estes próprios, são feitas ao mesmo tempo e normalmente com o mesmo fio. Nas rendas não-contínuas, o motivo costuma ser tecido separadamente e, durante a tecelagem da base, os mesmos são unidos por costuras praticamente invisíveis. Acredita-se que estes termos e essa forma de produzir rendas sejam característicos da Europa, visto que não foram identificados em nenhuma publicação brasileira. 
Aqui, conforme o Instituto Estadual do Patrimônio Cultural do Rio de Janeiro (1978), são empregados termos como "renda feita a metro", "rendas feitas em quadros" e "aplicações". As rendas feitas a metro, como o próprio nome indica, são produzidas para serem aplicadas em bordas ou entre dois tecidos. As rendas feitas em quadros são produzidas em formato quadrados, de tamanhos variados, que são posteriormente costuradas uma às outras com o objetivo de criar peças de grandes dimensões como toalhas de mesa e colchas de cama. As "aplicações" são rendas tecidas em formatos específicos de folhas, flores, animais e figuras que posteriormente são aplicadas em peças com o intuito de decoração. Porém, é o uso da renda que contribuirá para nomes específicos como: "entremeio" (possui duas ourelas) que tem a finalidade de unir dois tecidos, o qual também é conhecido como apegamento na região de Santa Catarina; "bico" que é a renda com ourela de um só lado, pois o outro lado apresenta pontas com formatos em "V" ou ondulados; e "aplicação" que é a renda que pode ser aplicada como bordado. Existem ainda as toalhinhas, paninhos, golas, gregas, galões (Instituto Estadual do Patrimônio Cultural-RJ, 1978).

Independente de seu uso, as rendas possuem os seguintes componentes básicos: base de ligação entre os desenhos, os desenhos ou motivos, bordas superior e inferior. Algumas apresentam ainda componentes complementares como fios de contorno nos desenhos e os picots.

A base de ligação é constituída por pontos que unem os desenhos. No caso de possuir um único desenho ou motivo, pode ser considerada como os pontos que unem o desenho à borda. Geralmente trata-se de uma rede que pode ser tecida com uma grande variedade de pontos ou barras, geralmente tecidas em ponto trança. Nas bases de ligação normalmente são empregados pontos diferentes dos utilizados para preenchimento dos desenhos, pois se tem como objetivo realça-lo e não competir. Nas atividades de estudo de identificação de rendas é por este componente que se inicia isto porque nas rendas europeias seus nomes são dados a partir da região onde são produzidas (Earnshaw, 1983).

O desenho de uma renda pode ser a representação de motivos florais, formas de animais, geométricos, orgânicos e abstratos. É na construção do desenho que pode ser empregada uma grande variedade de pontos, isso porque o ponto 
pode contribuir para enfatizá-lo na renda. Em meados do século XVII os desenhos que predominavam eram formas geométricas - triângulos, losangos e círculos, e formas abstratas. No decorrer do século XVIII praticamente todas as formas que conhecemos hoje foram inseridas na técnica (Earnshaw, 2000). Conforme Earnshaw (1983), cada região produtora pode ter milhares de desenhos e esta grande diversidade dificulta isolar características comuns de cada lugar, o que leva a autora a recomendar identificar local ou data a partir da análise visual de um desenho de renda. Somado a isso, atualmente muitos desenhos são reproduzidos em locais distantes de sua origem.

As bordas das rendas normalmente são retas, em curvas ou em bicos de diferentes graduações. Algumas rendas apresentam uma das bordas reta e a outra decorada, pois foram tecidas para serem costurada à outra peça (de vestuário, por exemplo). Já os entremeios têm as duas bordas retas, pois são produzidos para serem costurados nos dois lados. Tanto no nordeste quanto no sul, a borda da renda mais decorada tem o nome de ponta ou bico (sendo o primeiro mais usado no nordeste e o segundo no sul). Alguns exemplos: ponta-de-sobrancelha, ponta-decadarço, ponta-de-leque, rabo-de-pato, ponta-de-leque, etc.

Apesar da maioria das rendas de bilros não apresentarem áreas com volumes, alguns desenhos podem ser ornamentados com fios de contorno, usados para enfatizá-los. São fios com maior espessura que os utilizados na construção da base de ligação e nos desenhos em si. Além da espessura, o fio pode se diferenciar pelo brilho e matéria prima.

Por último temos os picots, nome usado para pequenas voltas ou laçadas empregadas na borda inferior, nas barras (tranças) que unem os desenhos ou nos próprios desenhos. Tem caráter decorativo e podem variar muito em tamanho e quantidade nas rendas. Apesar de ser um elemento decorativo que enriquece a renda, atualmente ele raramente é empregado, isso porque além de requerer muita habilidade, sua execução demanda um maior tempo para finalizar a renda fazendo com que as artesãs evitem tecê-lo para agilizar o trabalho. 
Em todos os componentes citados são empregados pontos, os quais, segundo Girão (2013), é a variação de movimento dos bilros que são basicamente cruzados e torcidos.

Existem ainda dois termos amplamente usados quando se trata de rendas de bilros que são: o "ponto da renda" e o "tipo de renda". O ponto de uma renda de bilros forma-se a partir da combinação dos movimentos dos bilros. Para Wendhausen (2015) esta movimentação forma pontos básicos, sendo os principais: meio ponto, pano (aberto, liso, fechado), torcido, perna-cheia e trança. Para Girão (2013), os pontos básicos ou "pontos padrões" são mais amplos, como por exemplo: traça, tijolo, besouro, búzio, aranha, pano-fechado, pano-aberto, etc. Conforme veremos mais adiante, já se percebe a existência de pontos em comum entre as duas regiões estudadas.

Quanto ao termo "tipos de renda", Wendhausen (2015) refere-se ao conjunto de pontos básicos e às figuras formadas por eles, resultando em nomes como: arco, corrupio, estrela, folha de café, margarida, mosquinha, olho de boi, rosinhas, entre outras. Para Girão (2013), o "tipo de renda" está vinculado a sua aplicação, por exemplo: toalhinha, golas, bicos, entremeio, etc.

\section{Pontos: estudo comparativo}

Aqui aprofundamos as questões sobre os pontos, focando em suas nomenclaturas e na comparação dos mesmos entre as regiões nordeste e sul do Brasil. Para tal foi estruturada uma lista com 61 pontos que constam no capítulo "Tipos de pontos" da publicação de Valdelice Girão (2013). Tais pontos foram levantados por Girão na coleção de rendas de Arthur e Luiza Ramos e da Coleção Rendas do Ceará. Girão iniciou o levantamento na década de sessenta e teve sua última versão em 2013. Na introdução a autora justifica que as nomenclaturas dos pontos baseiam-se na experiência que teve no Estado do Ceará. Salienta-se que além dos nomes, a análise das imagens dos pontos foi determinante, pois contribuíram em sua identificação. Somente pelo nome não seria possível compreendê-los e compará-los entre as duas regiões abrangidas no estudo. 
O Estado de Santa Catarina foi elencado para balizar e comparar com o estudo feito por Girão, pela importância e representatividade no cenário brasileiro de produção de rendas, além de estar distante geograficamente do Ceará. A publicação de Wendhausen (2015) aponta que a renda de bilros é considerada o maior ícone cultural da capital do Estado de Santa Catarina. Em sua publicação a autora elenca pontos, tipos de rendas, regiões produtoras, associações e projetos vinculados à produção de renda de bilros.

Visando um contraponto nas publicações e verificação na prática dos conteúdos e conceitos, foi feita visita às artesãs da Associação de Rendeiras de Sambaqui, de Florianópolis, para averiguar e consolidar aspectos teóricos e práticos sobre o estudo, bem como a comparação da nomenclatura dos pontos de renda de bilros. A Associação foi representada pela mestre rendeira Maria da Glória Viana Soares, a Dona Glorinha, importante nome da região, conhecida e respeitada pela colaboração em projetos e pelas artesãs da llha de Florianópolis.

Os 61 pontos que foram confrontados com a publicação de Wendhousen e apresentados à Associação de Rendeiras de Sambaqui são: 1) aranha, besouro ou mosca; 2) bananinha ou matachinha; 3) barata; 4) baratinha; 5) barafunda ou feitiço-de-quatro; 6) batuque (tringo ou charita); 7) búzio; 8) carreira; 9) carreiraaberta; 10) carreira-fechada; 11) cocada, tijolinho ou sopapinho; 12) coentrinho; 13) coentro; 14) coentro-trocado-dobrado; 15) Cordão ou bordão; 16) corrido; 17) crivo; 18) Dado ou traça-quadrado; 19) dois-trocados; 20) esteirinha; 21) favo-de-abelha; 22) filó; 23) grade ou palhetão; 24) jasmim; 25) meia-pancada; 26) meio-trocado; 27) melindre ou ponto-de-rato; 28) palhetão; 29) palma; 30) pancada-inteira; 31) paneira; 32) Paninho-meio-trocado; 33) pano (em forma de cocada); 34) pano-aberto ou pano-meio-trocado; 35) pano-batido; 36) pano-fechado; 37) pano-liso; 38) par-caído ou carreira-do-maranhão; 39) peneira; 40) picoti; 41) ponta-casco-de burro, 42) ponta-casco-de-besouro; 43) ponta-de-arrebite; 44) ponta-de-cadarço; 45) ponto-deespinho ou ponta de alfinete; 46) ponta-de-leque; 47) ponta-de-sombrancelha; 48) ponta-de-trança; 49) ponta-rabo-de-pato; 50) ponta-de-prata; 51) ponto solto; 52) torcidinho; 53) torcido ou trocado; 54) traça; 55) tramoia; 56) trança; 57) trança-compicot; 58) traça-de-dois; 59) trança-de-quatro; 60) trocado-cheio; 61) urupemba. 


\begin{tabular}{|l|l|l|}
\hline N. & \multicolumn{1}{|c|}{ REGIÃO NORDESTE } & \multicolumn{1}{c|}{ REGIÃO SUL } \\
\hline 1 & Aranha, besouro ou mosca & Aranha \\
\hline 5 & Barafunda ou feitiço-de-quatro & Olho de pombo \\
\hline 11 & Cocada, tijolinho ou sopapinho & Maria morena \\
\hline 15 & Cordão ou bordão & Cordão \\
\hline 18 & Dado ou traça-quadrado & Maria-morena \\
\hline 22 & Filó & Torcido \\
\hline 23 & Grade ou palhetão & Torcido quadrado \\
\hline 29 & Palma & perna-cheia \\
\hline 34 & Pano-aberto ou pano-meio-trocado & Meio-ponto \\
\hline 35 & Pano-batido & Pano \\
\hline 36 & Pano-fechado & Pano \\
\hline 37 & Pano-liso & Pano \\
\hline 40 & Picoti & Ponto falso \\
\hline 41 & Ponta-casco-de burro & Bico de pano \\
\hline 44 & Ponta-de-cadarço & Bico de arco \\
\hline 45 & Ponto-de-espinho ou ponta-de-alfinete & Ponto falso \\
\hline 49 & Ponta-rabo-de-pato & Rabo de pato \\
\hline 50 & Ponta-de-prata & Bico de pano \\
\hline 51 & Ponto solto & Ponto falso \\
\hline 53 & Torcido ou trocado & Torcido \\
\hline 54 & Traça & Perna-cheia \\
\hline 55 & Tramóia & Tramóia \\
\hline 56 & Trança & Trança \\
\hline 57 & Trança-com-picot & Trança com ponto falso \\
\hline
\end{tabular}

Tabela 2: Comparação dos nomes dos pontos da região nordeste e da região sul do Brasil.

(A autora)

A tabela 2 apresenta o resultado dos pontos da região nordeste reconhecidos no estudo feito na região sul.

Dos 61 pontos listados, apenas 24 são conhecidos na região sul, ou seja, $39,5 \%$. Salienta-se que, não só os nomes foram confrontados, mas as imagens também foram utilizadas para evitar equívocos e interpretações que não levassem ao objetivo desejado. Sem as imagens seria impossível construir o quadro comparativo, visto que pela análise somente dos nomes dos pontos o resultado seria em torno de 8 pontos reconhecidos.

Para exemplificar a importância das imagens no estudo, tem-se a publicação do Instituto Estadual do Patrimônio Cultural (1978), onde são mencionados apenas os nomes dos pontos (sem descrição ou imagem), havendo, portanto, a impossibilidade de saber se referem-se a algum ponto citado neste estudo. Alguns exemplos dos nomes mencionados: jibóia, viajante, cocada, morrogrande, pele-de-cobra, coração, Regina, rosa, rosinha, três-rosas, flor-do-dia, botahoje-tira amanhã, água-do-pote, coqueiro, entre muitos outros. 
Sem contar que, mesmo que o ponto tenha um mesmo nome, formalmente ele pode ser muito diferente. Por exemplo, a "palma" é muito diferente entre as regiões: no nordeste se caracteriza por um ponto de renda e, no sul, por um bico de renda.

As rendeiras catarinenses têm um repertório de pontos e combinações diferentes do cearense e isso ocorre nas diversas regiões do país em que a renda de bilros é produzida. Conforme Wendhausen (2015) mesmo dentro do litoral catarinense, os mesmos pontos podem mudar de nome. Earnshaw (2000) menciona que muitas confusões acontecem decorrentes de diversas nominações para os mesmos pontos.

As rendeiras procuram manter rigor ao nomear as rendas, isto porque elas insistem e se preocupam em manter a tradição. Assim, para que o ponto seja reconhecido por determinado nome, ele deve ser executado seguindo o rigoroso número de pares de bilros e suas movimentações. Por exemplo, para a renda receber o nome de tramóia deve, necessariamente, ser tecida com sete pares de bilros.

A partir do estudo dos pontos mencionados, analisando suas estruturas verifica-se que essencialmente há cinco diferentes pontos, podendo ser considerados como pontos de base, sendo eles: pano, pano aberto/meio-ponto, trança, traça/perna-cheia e torcido, ilustrados na Figura 3.

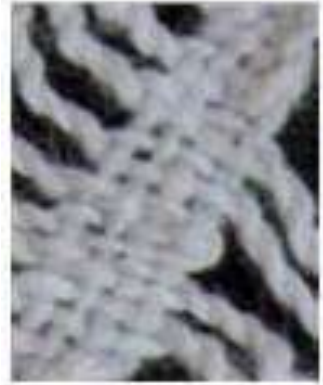

Pano

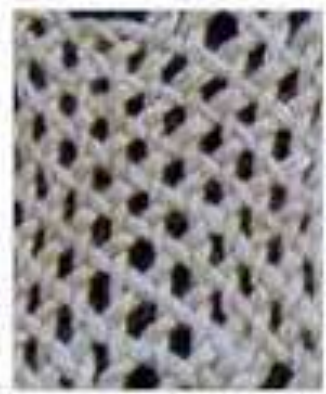

Pano abertol meio-ponto

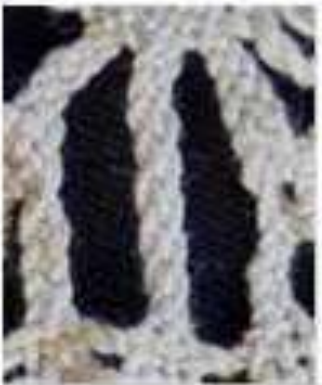

Trança

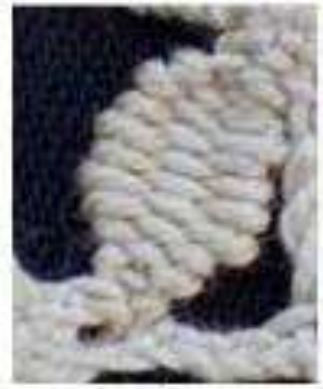

Traça/ Perna-cheia

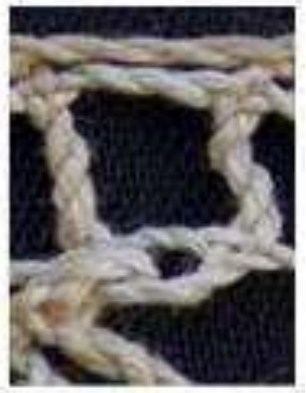

Torcido

Figura 3: Pontos básicos de renda de bilros. (Fotos: A autora)

É a partir da combinação, agrupamento e/ou repetição desses pontos que ocorrem as seguintes situações: 
a. formam-se outros pontos e, consequentemente uma nova nomenclatura. Por exemplo: o ponto perna-cheia/traça quando agrupado lado a lado a partir de um círculo concêntrico, forma a margarida.

b. nomeiam-se novas rendas. Por exemplo: o ponto pano, tramado com 7 pares de bilros, dá nome à renda tramoia.

c. pequenas alterações na forma já são suficiente para resultar e originar um novo ponto, por exemplo, a perna-cheia/traça quando tecida em um formato quadrado, chama-se de dado.

Portanto, a partir dos pontos mencionados são gerados uma infinidade de outros pontos, cuja nomenclatura reflete o contexto, cultura e tradição de onde são produzidas. Na referida lista dos nomes dos pontos (tabela 1) percebe-se que as nomenclaturas são muito peculiares levando a crer que são alegorias do cotidiano das rendeiras. Conforme Girão (2013, p.24): "De Norte a Sul vemos, pois, uma quantidade imensa de denominações, algumas altamente descritivas, outras arbitrárias e pitorescas, mas sempre facilmente reconhecidas pelas rendeiras".

Na pesquisa de Costa (2016) a situação também se confirma visto que a autora desenvolveu um estudo com objetivo de investigar, descrever e analisar o vocabulário das rendeiras do município de Raposa, no Maranhão. Verifica-se em sua pesquisa que alguns (poucos) nomes de pontos coincidiram com os aqui citados, mas também revelou muitas outras nomenclaturas que constitui 0 vocabulário peculiar das rendeiras daquela localidade.

\section{Considerações finais}

Conforme Girão (2013), a renda de bilros já representou o melhor "ganhapão" para mulheres rendeiras, entretanto reforça que este artesanato encontra-se em "completa decadência", ocasionado principalmente pelos baixos valores pagos e, concorrencialmente, pela atrativa rentabilidade de outros afazeres. Afirmação esta também confirmada compartilhada pelas rendeiras catarinenses.

Porém, mesmo em um cenário negativo e de incertezas e negativo verifica-se que algumas rendeiras e pessoas envolvidas com o meio são incansáveis 
nas atividades de promover e alertar para a importância desse patrimônio. Uma das muitas iniciativas catarinenses, por exemplo, é a manutenção de vínculos com a produção de renda de bilros de Portugal, principalmente da renda feita na llha dos Açores. Não só por conta da trajetória histórica da imigração açoriana, mas também por conta de projetos como "Renda de Bilro - de Santa Catarina aos Açores" que ocorreu em 2014 (Wendhausen, 2015). Projeto este, de cunho social e que levou rendeiras catarinenses aos Açores com o propósito de resgatar a renda de bilros nessa região portuguesa, onde a técnica praticamente desapareceu.

Neste contexto de preocupação de manutenção da técnica, torna-se muito importante o tema das nomenclaturas, um patrimônio imaterial que revela a criatividade que cerca o imaginário das rendeiras, que retrata tradições e representa culturas. Percebeu-se que cada localidade procura manter suas tradições e retratar suas peculiaridades. Apesar de muitas artesãs defenderem que o nome dos pontos não deve ser alterado, torna-se impossível conter as adaptações em função do contexto ou dos impulsos criativos, visto que a transmissão do conhecimento é feita de forma oral.

Neste estudo atinge-se o objetivo de reflexão de como são tratados os pontos de bilros nas regiões nordeste e sul do Brasil a partir das comparações de 61 pontos de renda conhecidos nessa primeira região. Teve-se como foco identificar quantos destes 61 pontos são reconhecidos na região sul, bem como apontar as nomenclaturas pelas quais são conhecidos, obtendo-se um resultado de 24 pontos comumente usados pelas artesãs da região sul e pela publicação de Wendhausen (2015), ou seja, 39,5\% do total. Percebeu-se também que muito importante foi a utilização das imagens no processo de identificação dos pontos. Caso as imagens dos pontos não tivessem sido consideradas o resultado alcançaria apenas 8 pontos de rendas fazendo com que o percentual caísse para $13 \%$. Reforçamos que os nomes sempre foram associados às imagens para evitar interpretações equivocadas.

Diante de tais resultados, explicitando a complexidade do vocabulário e a diversidade de pontos, conclui-se que a catalogação consiste em um processo fundamental e de extrema importância para o registro desse conhecimento 
construído pelas artesãs. Mesmo que os pontos e suas composições estão baseados em cinco pontos básicos, os mesmos se ramificam em formas, desenhos e tramados e, consequentemente, uma quantidade inimaginável de nomes de pontos, resultando em um campo para futuras pesquisas e investigações.

A contribuição de elencar os pontos de renda de bilros e compará-los visou fornecer subsídios para aumentar as possibilidades de compreensão dos contextos de produção de rendas em dois extremos do país. Revelou-se também a complexidade de um vocabulário que merece visibilidade pela representação de um patrimônio imaterial, um campo fértil para futuros estudos. Além disso, este estudo aproxima o vocabulário das duas regiões estudadas para os interessados em interagir neste contexto, seja por interesse de aprender a técnica, de desenvolver produtos junto às rendeiras ou pesquisas na área. Este estudo pode ser ampliado tanto no que diz respeito à inclusão de outros nomes de pontos, quanto no sentido que incluir outras regiões, visto que existem Estados como Maranhão, Bahia e Rio de Janeiro com importantes polos de produção de renda de bilros. Ou ainda, focar na análise da origem dos nomes, investigando e conectando o mundo de criatividade das artesãs com a prática de tecer rendas. 


\section{Referências}

ALMEIDA, Juliana D. Modelagem situada de metodologia da Oficina de Desenho de Renda de Bilro. 2010. Natal: 2010. Dissertação (Mestrado em Engenharia de Produção) - Centro de Tecnologia, Universidade Federal do Rio Grande do Norte. Natal, 2010.

BALBINOT, Gabriela; PEREIRA, Renata S; ZANELLA, Andrea V. A renda que enreda: analisando processos de constituir-se rendeira. Educação\&Sociedade, Vol. 21, n. 71. Campinas, jul., 2000. Disponível em: <http://www.scielo.br/scielo.php?script=sci_arttext\&pid=S0101-73302000000200011>. Acesso em: 10 fev. 2017.

BARROS, Kléber S. Análise antropotecnológica do desenvolvimento de novos produtos na produção artesanal: caso das rendeiras de bilro da Vila de Ponta Negra em Natal. Natal: 2009. Dissertação (Mestrado em Engrenharia de Produção) - Centro de Tecnológia, Universidade Federal do Rio Grande do Norte, Natal, 2009.

BRUSSI, Júlia Dias Escobar. Da "renda roubada" à renda exportada: a produção e a comercialização da renda de bilros em dois contextos cearenses. Dissertação Departamento de Antropologia da Universidade de Brasília. 2009

CARTILHA me ensina a fazer renda: princípios básicos da renda de bilros: histórico, elementos da renda, como fazer técnica básica, pontos básicos da renda. Florianópolis: HB Editora Valorizando o tempo, 2015.

CORDEIRO, Angela D. Rendeiras da Vila de Ponta Negra: o ensino da renda de bilro e de desenho como alternativa de continuidade de uma tradição de produção artesanal. Natal: 2010. Dissertação (Mestrado em Engenharia de Produção) - Centro de Tecnologia, Universidade Federal do Rio Grande do Norte, Natal, 2010.

COSTA, Raquel Pires. RENDAS, REDES E LENDAS: o vocabulário das rendeiras do município de Raposa, Maranhão. Programa de Pós-Graduação em Estudos Linguísticos da Faculdade de Letras da Universidade Federal de Minas Gerais. 2016

EARNSHAW, Pat. Bobbin \& Needle lace - Identifications and Care. London: Batsford Craft Ltda, 1983.

EARNSHAW, Pat. A dictionary of lace. London: Shire Publications Ltd, 1988.

EARNSHAW, Pat. The Identification of Lace. 3th. ed. London: Shire Publications Ltd, 2000

ETCHEVERRY, Delia. 2013. Encajes: história e identificación. Argentina: Fundación Museo Del Traje.

GANEM, M. 2013. Design dialógico: uma estratégia para gestão criativa de tradições. Dissertação, Bahia: Universidade Federal da Bahia.

GIRÃO, Valdelice Carneiro. Renda de bilros. Fortaleza: Instituto do Ceará, 2013.

INSTITUTO ESTADUAL DO PATRIMÔNIO CULTURAL DO RIO DE JANEIRO. Divisão de folclore: Rendeiras de Bilro no Estado do Rio de Janeiro. 2004. Disponível em: $<$ http://www.inepac.rj.gov.br/application/assets/img/site/RendeirasdeBilro.pdf> Acesso em 30 mar. 2017.

INSTITUTO DO PATRIMÔNIO HISTÓRICO E ARTÍSTICO NACIONAL. Patrimônio Imaterial. Disponível em: <http://portal.jphan.gov.br/pagina/detalhes/234> Acesso em 02 set. 2016.

MATSUSAKI, Bianca do Carmo. Trajetória de uma tradição: renda de bilros e seus enredos. Dissertação (Mestrado em Ciências) PPG em Têxtil e Moda. Universidade de São Paulo. São Paulo, 2016. 
MINITÉRIO DA CULTURA. Cultura em números: anuário de estatísticas culturais. $2^{\mathrm{a}}$ edição. Brasília: MinC, 2010. Disponível em: <http://culturadigital.br/ecocultminc/files/2010/06/Cultura-emN\%C3\%BAmeros-web.pdf> Acesso em 29 jul. 2017.

PALLISER, B.A. History of lace. London: Sampson, Low, Son, and Marston, 1869.

POWERHOUSE MUSEUM. Lace Study Centre. .Disponível em: $<$ http://www.powerhousemuseum.com/collection/database/?irn=132841\&search=bobbin+lace\&images $=\& \mathrm{C}=\& \mathrm{~S}=>$. Acesso em: 25 jul. 17 .

RAMOS, L.; RAMOS, A. A renda de bilros e sua aculturação no Brasil: nota preliminar e roteiro de pesquisa. Rio de Janeiro: Sociedade Brasileira de Antropologia e Etnologia, 1948.

SEBRAE. Estudo setorial artesanato. Disponível em: <http://www.biblioteca.sebrae.com.br/bds/bds.nsf/E1B356515E8B5D6D83257625006D7DA9/\$File/NT 00041F56.pdf>. Acesso em 31 Jul. de 2017.

SEBRAE. Bordados e rendas para cama, mesa e banho: estudos de mercado: 2008. Disponível em:

<http://www.bibliotecas.sebrae.com.br/chronus/ARQUIVOS_CHRONUS/bds/bds.nsf/CA146DA3D21F 877B832574DC00453EA0/\$File/NT00039052.pdf >. Acesso em: 31 jul. 2017.b.

UNESCO. Convenção para a salvaguarda do patrimônio cultural imaterial. Brasília: Ministério das Relações 2006.2 Disponível em: $<$ http://portal.iphan.gov.br/uploads/ckfinder/arquivos/Convenca0\%20Salvaguarda\%20Patrim\%20Cult \%20Imaterial\%202003.pdf> Acesso em 17 ago. 2017.

WENDHAUSEN, Maria Armênia Müller. Renda de bilros - um legado açoriano transcendendo séculos em Florianópolis. Blumenau: Nova Letra, 2015. 